\title{
EVALUASI KEPUASAN MAHASISWA TERHADAP KUALITAS PELAYANAN PENDIDIKAN LEMBAGA PENDIDIKAN TINGGI ABC DI CIKARANG
}

\author{
FARLIANA SUTARTIAH \\ farlianasutartiah@yahoo.com \\ Program Studi Teknik Industri - Fakultas Teknik, Matematika, dan IPA \\ Universitas Indraprasta PGRI
}

\begin{abstract}
Education is one service industry that provides services to students in need. One of Institute from Cikarang, Bekasi, west Java organized and developed the science, technology, and as a scientific community that is full of sublime imagery and educate the nation's life. The real conditions encountered by Institute is currently at in providing services to students especially on teaching staff (lecturers) as well as academic staff not yet optimal. An increase in the quality of service can be implemented using approach servqual. Servqual is a method for measuring the quality of service from a service provider. Quality of service is measured from each dimension (tangible, responsiveness, reliability, assurance, Empathize). For the result we know 5 element spread on 4 quadrant. Quadrant 1 are spread 6 things, Quadrant II are spread 11 thing, Quadrant III are spread 9 things and last Quadrant IV are spread 4 things. We investigate cause that need problem solving on Institute by Root Cause Analyze (RCA.) Based on the results of calculation and pay attention to the real conditions, interviews with students, obtained significant complaints with the research. In this case the Institute should improve the quality of service, both in terms of performance of teaching staff, and the number of teaching staff for teaching and learning process can be going well, so does the relationship of administration and facility staff and other supporting improved.
\end{abstract}

Keywords: quality, service, Servqual, satisfaction, RCA

\section{PENDAHULUAN}

Mahasiswa adalah pelanggan utama perguruan tinggi, sudah seharusnya pelayanan pendidikan tinggi harus berorientasi kepada mahasiswa. Alifudin (2012) meyatakan bahwa mengingatkan bahwa pelayanan pendidikan memang merupakan hak mahasiswa yang wajib dipenuhi perguruan tinggi sebagai penyedia jasa. Oleh karena itu, menurut Aliffudin kurang tepat apabila memaknai konsep pelayanan pendidikan hanya dalam spektrum kompetisi antar perguruan tinggi.

Salah satu instansi pendidikan di Cikarang adalah pendidikan tinggi swasta. lembaga pendidikan ini mempunyai 3 jurusan yaitu Manajemen Perkantoran, Ilmu Komputer dan Komputer Akuntansi. Pada kampus ini melayani perkuliahan, Praktikum, Administrasi dan Perpustakaan. Untuk memberikan mutu pelayananan yang baik harus melakukan perbaikan berkelanjutan terhadap pelayanan yang selama ini diberikan. Agar perbaikan menunjukkan hasil yang signifikan, maka perlu mengetahui layanan yang dirasa mahasiswa perlu ditingkatkan.

Berdasarkan survei pendahuluan yang dilakukan dengan melakukan wawancara terhadap 30 orang responden mahasiswa, untuk mengetahui sebaran keluhan terhadap pelayanan kampus. Agar lebih terfokus maka penelitian ini dilakukan pada kegiatan pelayanan pendidikan. Sejumlah $53 \%$ keluhan terhadap kegiatan perkuliahan. Sejumlah $15 \%$ keluhan terhadap kegiatan praktikum. Sedangkan $32 \%$ keluhan terhadap pelayanan perpustakaan serta pelayanan administrasi. 
Kepuasan mahasiswa terkait erat dengan kesesuaian antara harapan dan kenyataan dari kualitas pelayanan pendidikan yang didapat dari kampus tersebut. Apabila lembaga pendidikan ini memperlakukan mahasiswa sebagai pelanggan dengan mengevaluasi kesenjangan antara harapan dan kenyataan yang dirasakan mahasiswa terhadap kualitas pelayanan pendidikan, maka kampus ini dapat menyiapkan rencana strategis yang tepat untuk meningkatkan kualitasnya. Evaluasi kepuasan mahasiswa ini dapat digunakan untuk mengetahui faktor-faktor kualitas pelayanan pendidikan yang perlu diperbaiki, dipertahankan, bahkan dikurangi akan mengakibatkan kesalahan alokasi sumber daya seperti dana, tenaga kerja, dan waktu. Kesalahan alokasi sumber daya menyebabkan upaya peningkatan mutu menjadi tidak efektif dan mengurangi kepuasan mahasiswa.

Untuk menelaah kepuasan mahasiswa terkait kualitas, pelayanan kampus politeknik ini diperlukan instrumen pengukuran yang tepat. Karena selama beberapa tahun, para peneliti akademis telah mencoba mengukur kualitas jasa dalam perguruan tinggi dengan skala satu dimensi.

\section{METODE}

Penelitian ini disusun untuk menggambarkan konsep analisis kepuasan mahasiwa melalui penilaian harapan dan kenyataan kualitas pelayanan pendidikan di kampus dari sisi mahasiswa sebagai pengguna jasa. Analisis kepuasan mahasiswa terhadap pelayanan pendidikan di kampus ini diperlukan karena semakin ketatnya persaingan antara politeknik sejenis. Untuk dapat memenangkan kompetisi, kampus ini harus melakukan perbaikan kualitas berkesinambungan. Perbaikan kualitas ini dapat dimulai dengan menganalisis kepuasan mahasiswa sebagai pelanggan utama yang merasakan pelayanan pendidikan di kampus ini.

Konsep yang digunakan untuk mengukur tingkat kualitas pelayanan pendidikan di Polieknik ini dilihat dari lima dimensi kualitas pelayanan jasa menurut Parasuraman, Zeithaml, dan Berry (1988) yaitu tangible, reliability, responsiveness, assurance, dan empathy yang disebut dengan SERVQUAL. Masing-masing dimensi SERVQUAL dituangkan dalam beberapa atribut pertanyaan. Analisis univariat yang dilakukan ialah analisis kesenjangan antara harapan dan kenyataan mahasiswa, analisis tingkat kesesuaian kepuasan akan kualitas pelayanan, serta analisis uji beda. Hasil analisis kesenjangan tersebut kemudian dipetakan prioritasnya dalam Importance-Performance Analysis. Penelitian ini juga menilai adakah hubungan yang bermakna antara karakteristik mahasiswa sebagai pengguna jasa terhadap penilaian kualitas pelayanan pendidikan Politeknik. Adapun kerangka penelitian ini dapat dilihat pada gambar 1.

\section{HASIL DAN PEMBAHASAN}

Dalam penentuan kualitas pelayanan pendidikan mahasiswa dilakukan dengan menghitung tingkat kepuasan mahasiswa terhadap mutu pelayanan pendidikan di kampus melalui kenyataan layanan yang diterima dan harapan mahasiswa terhadap pelayanan kampus. Pengukuran tingkat kepuasan (kualitas mutu pelayanan pendidikan Kampus) dilakukan dengan melakukan perbandingan antara kenyataan atas layanan yang diterima dengan harapannya sehingga didapat tingkat kesesuaian terhadap pelayanan kampus. Hal ini dinilai mencerminkan kualitas pelayanan pendidikan kampus dalam bentuk persen kesesuaian. 


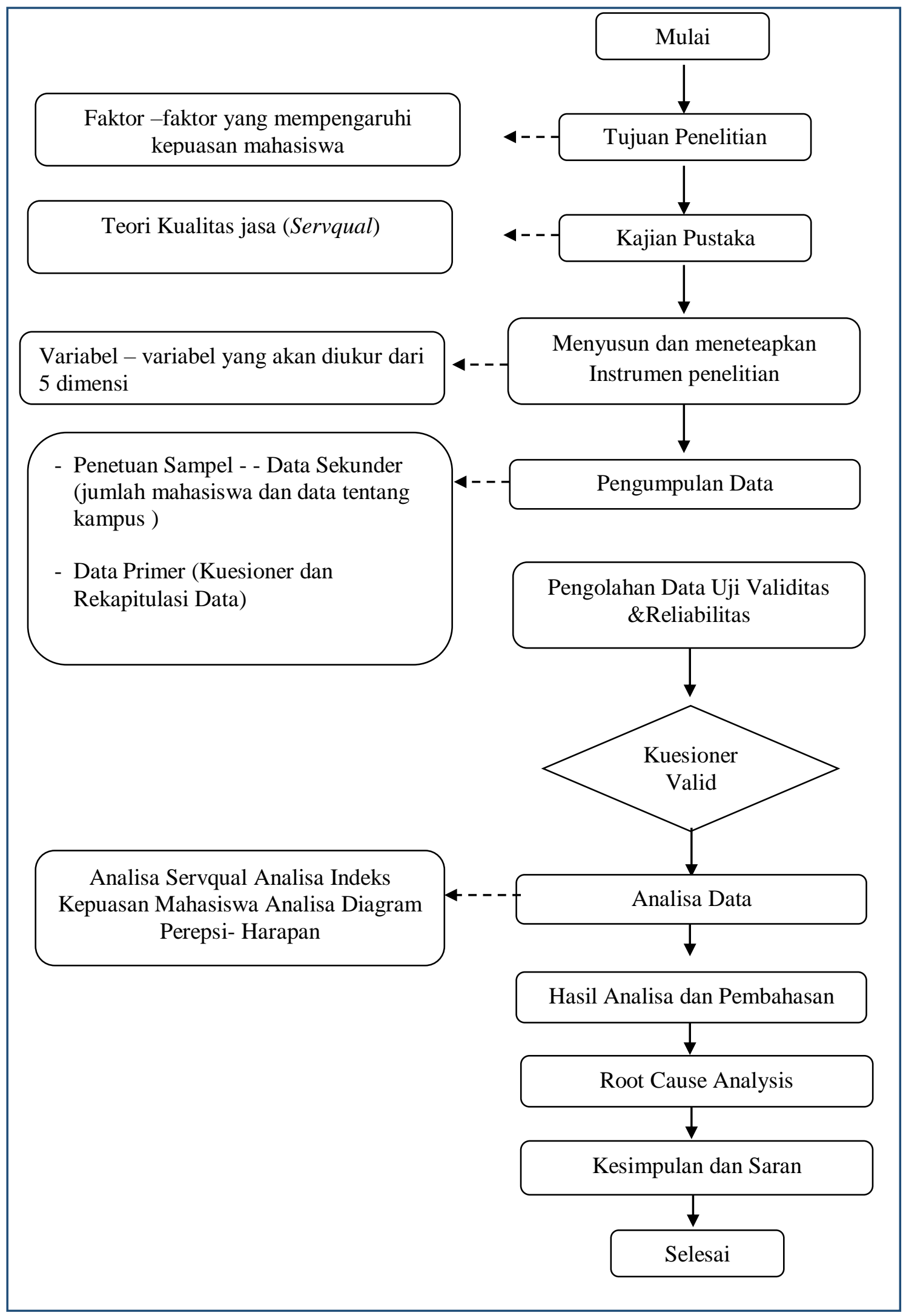

Gambar 1. Kerangka penelitian 
Kualitas pelayanan kampus kemudian dikategorikan berdasarkan nilai cut-off point kepuasan. Menurut Yuliana (2009), penentuan cutoff point dapat dilakukan dengan terlebih dahulu melihat distribusi data. Apabila sebaran data data normal, maka menggunakan nilai mean sebagai standar cut-off point. Jika datanya berdistribusi tidak normal, maka menggunakan nilai median. Karena rerata total seluruh dimensi adalah 100,97\%, maka nilai tersebut ditetapkan sebagai cut-off point. Sehingga persen kesesuaian kualitas pelayanan dengan nilai lebih dari 100,97\% berada dalam kategori baik dan persen kesesuaian dengan nilai $<100,97 \%$ dikategorikan sebagai kurang baik. Dengan demikian, kualitas pelayanan pendidikan di kampus dapat dikategorikan ke dalam kategori baik jika besar persen kesesuaiannya $\geq 100,97 \%$ dan jika persen kesesuaiannya $<100,97 \%$ maka kualitas pelayanan kampus dikategorikan kurang baik.

\begin{tabular}{|c|c|c|c|c|c|c|c|c|}
\hline $\mathrm{N}$ & Item & \multirow[b]{2}{*}{ Dimensi } & \multicolumn{2}{|c|}{ Rerata Kenyataan } & \multicolumn{2}{|c|}{ Rerata Harapan } & \multicolumn{2}{|c|}{ Kesesuaian } \\
\hline o & Pertanyaan & & Item & Dimensi & Item & Dimensi & Item & Dimensi \\
\hline 1 & Ruang Kuliah & & 2.988 & & 2.963 & & 100.844 & \\
\hline 2 & $\begin{array}{l}\text { Fasilitas } \\
\text { pendukung }\end{array}$ & & 3.175 & & 3.075 & & 103.252 & \\
\hline 3 & $\begin{array}{l}\text { Penampilan } \\
\text { Dosen }\end{array}$ & & 2.988 & & 3.050 & & 97.951 & \\
\hline 4 & $\begin{array}{l}\text { Penampilan } \\
\text { Pegawai }\end{array}$ & Tangible & 3.238 & 3.102 & 3.113 & 3.057 & 104.016 & 101.460 \\
\hline 5 & $\begin{array}{l}\text { Parkir } \\
\text { Kendaraan }\end{array}$ & & 3.150 & & 3.000 & & 105.000 & \\
\hline 6 & Keraturan TU & & 3.163 & & 3.075 & & 102.846 & \\
\hline 7 & Kamar Mandi & & 3.013 & & 3.125 & & 96.400 & \\
\hline 8. & $\begin{array}{l}\text { Pegawai Tepat } \\
\text { Waktu }\end{array}$ & & 3.225 & & 3.075 & & 104.878 & \\
\hline 9 & Dosen Tepat & & 3.000 & & 2.913 & & 103.004 & \\
\hline 10 & $\begin{array}{l}\text { Waktu } \\
\text { Administrasi }\end{array}$ & Reliability & 3.163 & 3.150 & 2.938 & 3.035 & 107.660 & 103.789 \\
\hline 11 & Akademis & & 3.225 & & 3.175 & & 101.575 & \\
\hline 12 & $\begin{array}{l}\text { Kejelasan } \\
\text { Informasi }\end{array}$ & & 3.138 & & 3.075 & & 102.033 & \\
\hline 13 & $\begin{array}{l}\text { Pelayanan } \\
\text { Pegawai Cepat }\end{array}$ & & 3.300 & & 3.050 & & 108.197 & \\
\hline 14 & Pegawai & & 3.100 & & 3.138 & & 98.805 & \\
\hline 15 & $\begin{array}{l}\text { Tanggap } \\
\text { Dosen Mudah } \\
\text { dihubungi }\end{array}$ & $\begin{array}{l}\text { Responsi } \\
\text { veness }\end{array}$ & 2.900 & 3.125 & 3.113 & 3.094 & 93.173 & 101.010 \\
\hline 16 & $\begin{array}{l}\text { Dosen } \\
\text { Tanggap }\end{array}$ & & 3.200 & & 3.075 & & 104.065 & \\
\hline 17 & $\begin{array}{l}\text { Jaminan Masa } \\
\text { Depan }\end{array}$ & & 2.700 & & 2.963 & & 91.139 & \\
\hline 18 & $\begin{array}{l}\text { Kerahasiaan } \\
\text { Informasi } \\
\text { Akademik }\end{array}$ & & 2.938 & & 3.088 & & 95.142 & \\
\hline 19 & $\begin{array}{l}\text { Kurikulum } \\
\text { Sesuai }\end{array}$ & Assurance & 3.038 & 2.925 & 3.125 & 3.070 & 97.200 & 95.277 \\
\hline 20 & $\begin{array}{l}\text { Kompetensi } \\
\text { Pegawai }\end{array}$ & & 2.938 & & 3.163 & & 92.885 & \\
\hline 21 & $\begin{array}{l}\text { Harapan } \\
\text { Kompetensi } \\
\text { Dosen }\end{array}$ & & 3.013 & & 3.013 & & 100.000 & \\
\hline
\end{tabular}




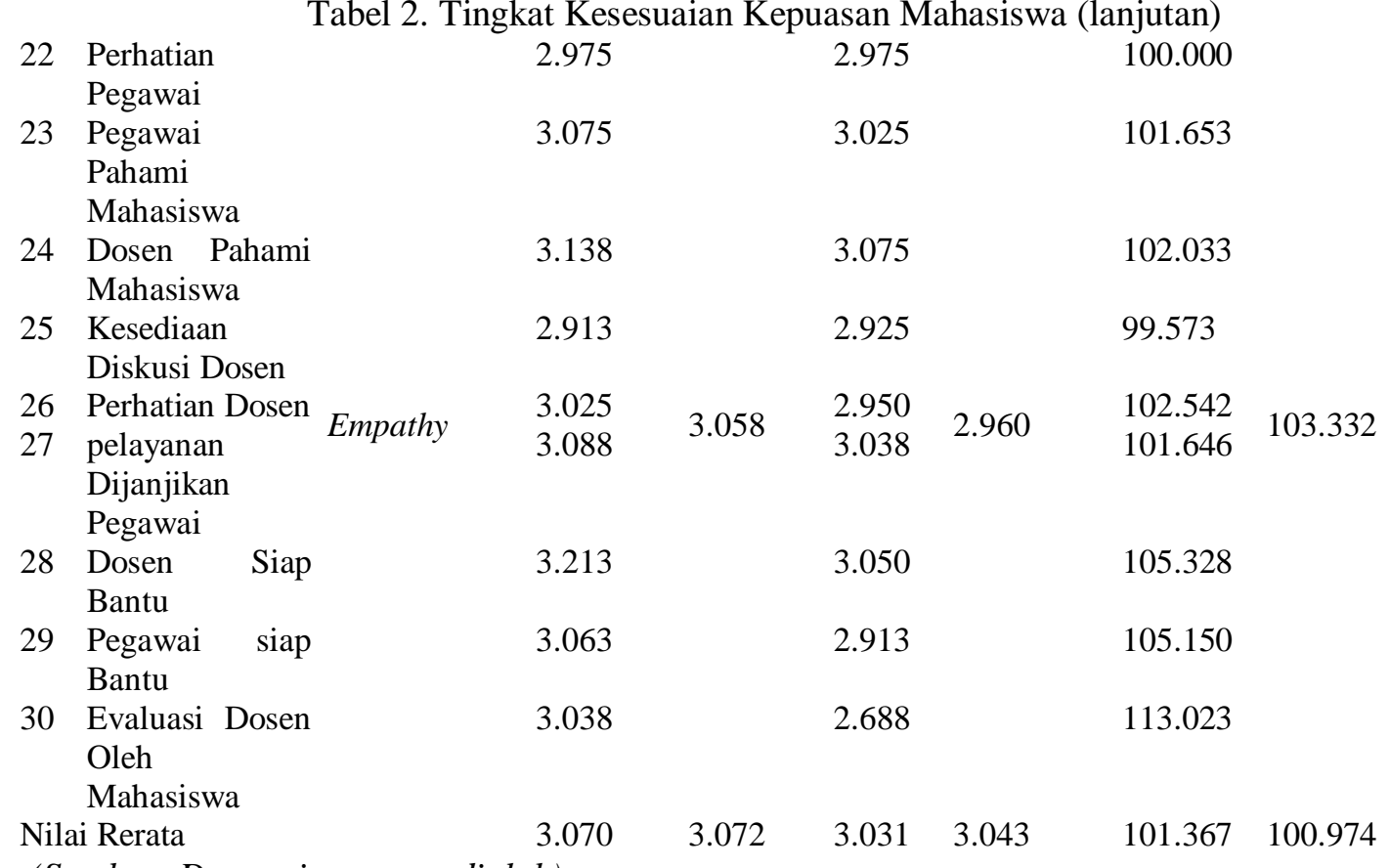

(Sumber: Data primer yang diolah)

Dari tabel di atas, terlihat bahwa terdapat 12 atribut pertanyaan yang dikategorikan kurang baik, yaitu atribut ruang kuliah, penampilan dosen, kamar mandi, pegawai tanggap, dosen tanggap, jaminan masa depan, kerahasiaan informasi akademik, kurikulum sesuai, kompetensi pegawai, kompetensi dosen, perhatian pegawai, dan kesediaan diskusi dosen. Seluruh dimensi pelayanan pendidikan kampus kecuali assurance $(95,28 \%)$ masuk dalam kategori baik.

Penentuan kualitas pelayanan dari sisi mahasiswa sebagai pengguna layanan kampus ditentukan berdasarkan nilai skor kenyataan atas pelayanan yang dirasakan mahasiswa dibandingkan dengan skor harapan dalam bentuk persentase kesesuaian. Dari hasil perhitungan diketahui bahwa persen kesesuaian terendah adalah jaminan masa depan 91,14\% dan persen kesesuaian tertinggi adalah respon EDOM 113,02\%. Dimensi pelayanan yang memiliki nilai kesesuaian paling tinggi adalah reliability $(103,789 \%)$, diikuti dimensi empathy(103,332\%). Sementara dimensi pelayanan dengan nilai kesesuaian terendah adalah assurance yakni 95,277\%.

Kualitas pelayanan ini terus dievaluasi dan diperbaiki karena penyelenggaran kampus menyadari bahwa kecepatan peningkatan mutu penyelenggaraan pendidikan tidak selalu sebanding dengan peningkatan tuntutan masyarakat.

\section{Uji Beda Kenyataan dan Harapan}

Salah satu analisis statistik yang digunakan dalam penelitian ini adalah uji beda ttest. Dari 80 responden yang diteliti terlihat bahwa rata-rata pendapat mahasiswa mengenai Kenyataan pelayanan pendidikan Politeknik $\mathrm{ABC}$ adalah 3,07, dan rata-rata Harapan mahasiswa terhadap hal yang sama adalah 3,03. 
Tabel 3. Nilai Rerata Kenyataan dan Harapan

$\begin{array}{llll} & \text { Rerata } & \text { N } & \text { Standar Deviasi } \\ \text { Kenyataan } & 3,07 & 80 & 0,275 \\ \text { Harapan } & 3,03 & 80 & 0,253\end{array}$

(Sumber: Data primer yang diolah)

Dari hasil uji beda tersebut terlihat bahwa rata-rata perbedaan antara kenyataan dengan harapan adalah sebesar 0,039. Hal ini menunjukkan kenyataan lebih besar dibandingkan harapan, dengan degree of freedom (df) atau derajat kebebasan uji adalah 79. Hasil perhitungan nilai " $t$ " adalah sebesar 1.335 dengan signifikansi $p$-value 0.186 (uji 2-arah). Hal ini berarti bahwa pada mahasiswa secara statistik tidak memiliki perbedaan yang bermakna antara rata-rata kenyataan dan harapan.

Tabel 4. Uji Beda Kenyataan dan Harapan

\begin{tabular}{|c|c|c|}
\hline Rerata & & $\begin{array}{l}\text { Kenyataan - Harapan } \\
0,039\end{array}$ \\
\hline Standar Deviasi & & 0,263 \\
\hline 95\% Confidence Interval of the Difference & & $-0,019294$ \\
\hline & $\begin{array}{l}\text { Lower } \\
\text { Upper }\end{array}$ & 0,097819 \\
\hline $\mathrm{T}$ & & 1,335 \\
\hline Df & & 79 \\
\hline $\begin{array}{l}\text { Sig (2-tailed) } \\
\text { (Sumber: Data primer yang diolah) }\end{array}$ & & 0,186 \\
\hline
\end{tabular}

Sebagaimana Kotler (2009) menerangkan kepuasan adalah perasaan senang atau kecewa seseorang yang muncul setelah membandingkan kinerja produk atau jasa yang diterima terhadap yang diharapkan. Jika kinerja berada di bawah harapan, pelanggan tidak puas. Jika kinerja memenuhi harapan, pelanggan puas. Jika kinerja melebihi harapan, pelanggan amat puas atau senang. Maka mahasiswa sebagai pelanggan dapat dikatakan puas terhadap pelayanan pendidikan.

Akan tetapi, kepuasan mahasiswa perlu dikaitkan dengan konsep Zone of Indifference (ZOI). Mahasiswa dapat dikatakan sangat puas (delight) jika hasil positif uji beda kenyataan dan harapan juga didukung dengan nilai signifikansi atau kebermaknaan dari perbedaan tersebut. Sementara hasil uji beda positif antara kenyataan dan harapan mahasiswa tidak memiliki perbedaan bermakna, sehingga dalam konsep ZOI disebut dengan istilah kepuasan indifferent positive. Apabila uji beda menghasilkan nilai negatif dengan perbedaan tidak bermakna, maka disebut sebagai penerimaan (acceptance) indifferent negative. Berkebalikan dengan sangat puas, maka ketidakpuasan menurut uji beda adalah apabila hasil negatif dan nilai perbedaannya signifikan.

\section{Importance-Performance Analysis}

Setelah dilakukan uji kesenjangan antara kenyataan dan harapan dilakukan analisa dengan Importance Performance Analysis menggunakan software SPSS 20. Dari beberapa plot yang didapatkan pada gambar 2. diidentifikasi prioritas yang akan membantu dalam proses peningkatan mutu pelayanan. Leebov (1993) menyatakan makna dari kuadran-kuadran tersebut adalah: 


\section{Kuadran I}

Ini adalah wilayah yang memuat faktor-faktor yang memiliki nilai harapan tinggi dari sudut pandang pelanggan tetapi pada kenyataannya kenyataan yang diperoleh masih sangat rendah. Variabel-variabel masuk dalam kuadran ini harus ditingkatkan dengan cara perusahaan tetap berkonsentrasi pada kuadran ini. Pada kuadran ini terdapat enam atribut.

2. Kuadran II

Ini adalah wilayah yang memuat faktor-faktor yang memiliki nilai harapan tinggi dari sudut pandang pelanggan dan dalam kenyataan pelanggan, pelayanan yang didapat sudah sesuai dengan yang diharapkan. Variabel-variabel yang termasuk dalam kuadran ini harus tetap dipertahankan, karena variabel ini yang menjadikan produk tersebut memiliki keunggulan di mata pelanggan. Pada kuadran ini terdapat enam atribut.

3. Kuadran III

Dalam wilayah ini, pelanggan tidak memiliki harapan tinggi terhadap faktor-faktor yang ada. Kenyataan atas kualitas pelayanan yang didapat pelanggan pun biasa saja atau tidak terlalu istimewa. Variabel-variabel yang termasuk dalam kuadran ini memiliki pengaruh kecil terhadap manfaat yang dirasakan oleh pelanggan. Pada kuadran ini terdapat lima atribut.

4. Kuadran IV

Dalam wilayah ini, pelanggan tidak memiliki harapan tinggi terhadap faktor-faktor yang ada. Akan tetapi, dalam pelayanan yang diterima pelanggan, nilai kenyataannya tinggi, sehingga dirasakan terlalu berlebihan. Variabel -variabel yang termasuk dalam kuadran ini dapat dipertimbangkan untuk dikurangi, sehingga perusahaan dapat menghemat biaya. Ada 5 antribut yang menempati kuadran IV ini. Berikut adalah gambar matriks importance performance analysisnya.

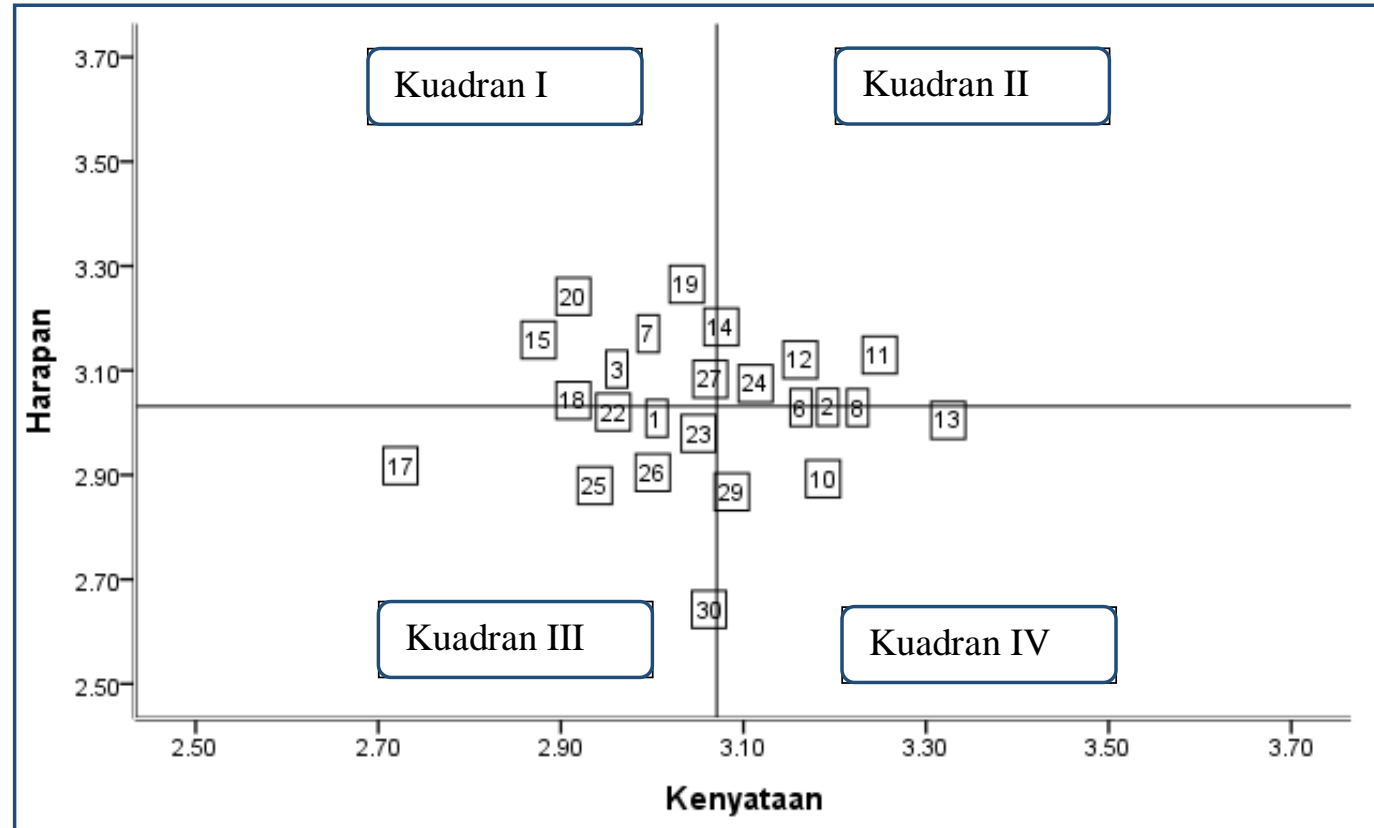

Gambar 2. Matriks Importance Performance Analysis Pelayanan pendiikan Sumber: Data yang diolah 


\section{PENUTUP}

Semakin ketatnya persaingan dengan perguruan tinggi yang membuka program studi sejenis baik di negeri maupun swasta meningkatkan urgensi evaluasi dan perbaikan mutu penyelenggaraan pendidikan dalam pelayannya kepada mahasiswa. Karena itu perlu diadakan evaluasi kualitas pelayanan pendidikan secara berkala.

Berdasarkan hasil pengujian terhadap data dari 80 responden penelitian, maka dapat diambil kesimpulan sebagai berikut:

1. Tingkat kenyataan mahasiswa lembaga pendidikan tinggi $\mathrm{ABC}$ terhadap kualitas pelayanan akademik mempunyai nilai rata - rata sebesar 3.072 dengan nila masing masing aspek sebagai berikut: reliability sebesar 3.15, responsiveness sebesar 3.125, assurance sebesar 2.925, emphaty sebesar 3.058 dan tangible sebesar 3.102.

2. Tingkat harapan mahasiswa lembaga pendidikan tinggi $\mathrm{ABC}$ terhadap kualitas pelayanan akademik mempunyai nilai rata -rata sebesar 3.043 dengan nilai masing masing aspek sebagai berikut: reliability sebesar 3.035, responsiveness sebesar 3.094, assurance sebesar 3.070, emphaty sebesar 2.960 dan tangible sebesar 3,057.

3. Bahwa nilai harapan lebih tinggi dari nilai persepsi. Nilai kualitas pelayanan akademik lembaga pendidikan tinggi $\mathrm{ABC}$ adalah 0.039. dengan nilai pada masing masing dimensi sebagai berikut: reliability sebesar 0.115 , responsiveness sebesar 0.031, assurance sebesar -0,145, emphaty sebesar 0.099 dan tangible sebesar 0.045. nilai gap negatif pada assurance sebesar -0.145 .

Sedangkan untuk analisis IPA (Importance Performance Anlysis), dapat dijabarkan sebagai berikut:

a. Kuadran I, item pernyataan yang masuk ke dalam kategori item ini adalah pernyataan no. $3,7,15,18,19$ dan 20 dimana kebanyakan item tersebut berada pada dimensi assurance.

b. Kuadran II, item pernyataan yang masuk ke dalam kategori ini adalah item pernyataan no. $2,4,6,8,11,12,13,14,16,24$, dan 27 dimana pernyataan terbanyak terdapat pada dimensi responsiveness.

c. Kuadran III, item pernyataan yang masuk ke dalam kategori ini adalah item pernyataan no. 1, 9, 17, 21, 22, 25, 26, 29, dan 30 dimana pernyataan terbanyak pada dimensi emphaty.

d. Kuadran IV, item pernyataan yang masuk ke dalam kategori ini adalah item pernyataan no. $5,10,23$, dan 28 .

\section{DAFTAR PUSTAKA}

Alifuddin, M. (2012). Reformasi Pendidikan: Strategi Inovatif Peningkatan Mutu Pendidikan. Jakarta: Magna Script.

Alma, B. (2009). Manajemen Corporate dan Strategi Pemasaran Jasa Pendidikan: Fokus Pada Mutu dan Layanan Prima. Bandung: Alfabeta.

Arief, M. (2007). Pemasaran Jasa dan Kualitas Pelayanan, Bagaimana Mengelola Kualitas Pelayanan Agar Memuaskan Pelanggan. Malang: Banyumedia.

Assauri, S. (2002). Manajemen Pemasaran: Dasar-Dasar, Konsep, dan Strategi. Jakarta: Raja Grafindo Persada.

Brady \& James. (2001). Searching for a Consensus on the Antecedent Role of Service Quality and Satisfaction: exploratory Cross - National Study. Journal of Business research, 51(2), 143 -159.

Bieber, G. (2006). Cervical Cancer Screening in Clinical Gynecology. Philadelphia:

Churchill Livingstone Elsevier, 121 -141. 
Bolton. R., \& Drew, F. (2001). Aresponese for California's Mandated Nursing ratios. Journal Nurse Scholarship.35 (2). 179 - 84.

Chopra, R., Chawla, M., \& Sharma, T. (2014). Service Quality in Higher Education: A Conparative Study of Management and Education Institutions. Journal of Business research, 7(8), $175-191$.

Petters, M. and Roberts, P. (1999). Virtual Technologies and Tertiary Education. Palmerston North: Dunmore Press. Journal of Business research, 3(4), 212 232.

Gaspersz, V. (2011). Total Quality Management. Jakarta: Gramedia Pustaka Utama.

Ghibran, B., \& Lee H. (2014). Graduated Entrepreneurship In The Developing World: Intentions, Education and Development. Journal of Business research, 2(5), $175-184$.

Gold, E. (2001). Customer Service: A Key Unifying for Today's Campus. Journal of Netresults, National Association of Student Personnel Administration, 5(4), 154 173.

Khodogari, F., \& Khodogari, B. (2011). Service Quality in Higher Educations. Case Study: Measuring service quality of Islamic Azad University, Firoozkoh Branch. Journal of service quality research, 4(2), $234-251$.

Honeysha, R.M., Hilman,H. \& Waroka,A. (2011). Service Quality and students Satifiscation at Hihger Learning Institution: The Compering Dimensions of Malaysian University Competiveness.Journal of Business. 43 (3), 100-121.

Irawan, H.(2003). Indonesian Customer Satisfaction: Membedah Strategi Kepuasan Pelanggan Merek Pemenang ICSA. Jakarta: Gramedia Pustaka Utama.

Jasfar, F. (2005). Manajemen Jasa. Bogor: Ghalia Indonesia.

Javadi, M.(2011).Quality Assessment for AcademicServices in University of IsfahanAccording to the Students' Opinion Using SERVQUAL Model.Interdisciplinary Journal of Contemporary Research in Business, 3(4), $129-150$.

Jogiyanto, H.M. (2008). Analisis dan Desain Sistem Informasi: Pendekatan.TerstrukturTeori dan Praktik Aplikasi Bisnis. Yogyakarta: Andi. Kotler, P. (2000). Manajemen Pemasaran. Jakarta: Indeks.

Kotler, P., \& Keller, B. (2009). Manajemen Pemasaran Analisis, Perencanaan, Implementasi, dan Pengendalian. Jakarta: Erlangga.

Landrum, H. (2009). Measuring Is System service quality with servqual, users perceptions of relative importance of the five servperf dimensions. The international journal of an emerging transdiscipline, 12(3), 178-196.

Leebov, W. (2003). The Health Care Manager's Guide to Continuous QualityImprovement. London: Universe.

Lupiyoadi, R. (2008). Manajemen Pemasaran Jasa. Jakarta: Salemba Empat.

Martins, N., \& Dastone, O. (20014). Service Quality Gap for Private Higher Institutions

(Hels) in Malaysia: African Student perspective. Journal of Research, 2 (1), 167 -175 .

Mosadeghard, A.M. (2006). The Impact of Organizatonal Culture On The Susscesful Implementation of Total Quality Management. The TQM Magazine, 18 (6). 192 $-200$.

Minor, M. (2002). Perilaku Konsumen. Jakarta: Erlangga.

Nielsen, A.C. (2010).SES (Socio-Economic Status) Indonesia. http://vidinur.com/2010/11/04/ses-socio-economic-status.

Nurgiyantoro, B. (2009). Statistik Terapan Untuk Penelitian Ilmu-Ilmu Sosial. Yogyakarta: Gadjah Mada University Press. 
Parasuraman, A., Zeithaml, V., dan Berry, L. (1988). Servqual: A Multiple-Item Scale for Measuring Consumer Perceptions of Service Quality.Journal of Retailing, 64 (1), $157-162$.

Parasuraman, A., Zeithaml, V., dan Berry, L. (1991). Refinement and Reassessment of the SERVQUAL Scale. Journal of Retailing, 67 (4), 75 -89.

Parasuraman, A., Zeithaml, V., dan Berry, L. (1996). A Conceptual Model of Service Quality and Its Implications for Future Research. Journal of Marketing, 49 (2), $241-260$.

Parasuraman, A., Zeithaml, V., dan Berry, L. (2008). Delivering Quality Service. Canada: The Free Press.

Priyatno, D. (2010). Teknik Mudah dan Cepat Melakukan Analisis Data Penelitian Dengan SPSS. Yogyakarta: Gava Media.

Ramscook, P. (2010). Service Quality in The Public Service. Journal of marketing, 3 (1), $133-151$.

Qureshi, T.M. (2010). Service Quality SERVQUAL Model in Higher Educational Institutions, What Factors are to be Considered? Interdisciplinary Journal of Contemporary Research in Business, 2 (5),154 - 172.

Qureshi, Q.A. (2014). Impact of Service Quality on Customer satisfaction in Higher Education Institution. Interdisciplinary Journal of Contemporary Research in Business, 4 (3), $142-159$.

Shekarchizadeh, A. (2011). SERVQUAL in Malaysian Universities: Perspectives of international students. Business Process Management Journal,17 (1), 164 - 176.

Sinaga, R. (2010). Analisis PengaruhKualitas Pelayanan Kepuasan Pelanggan dan Lokasi Terhadap Loyalitas Pelanggan (Studi kasus pada warnet chanber Semarang): Universitas Diponegoro, Semarang.

Sudjana. (1996). Teknik Analisis Regresi dan Korelasi. Bandung: Tarsito.

Sugiyono (2004). Statistika Untuk penelitian. Bandung: CV. Alfabeta

Tjiptono, F. (2008). Manajemen Jasa. Yogyakarta: Andi.

Tjiptono, F. (2012). Service Management: Mewujudkan Layanan Prima. Yogyakarta: Andi.

Yasin, A., \& Mohammad, A. (2014). Service Quality Provided by Higher education Instituions in Somalia and Its Impact on Student Satisfaction. Journal of Marketing, 6(1). $243-266$. 